\title{
Body weight changes in breast cancer patients following adjuvant chemotherapy and contributing factors
}

\author{
JIAN-SHENG WANG $^{1 *}$, HUI CAI $^{1 *}$, CHANG-YAN WANG $^{1 *}$, JIA ZHANG $^{1}$ and MING-XIN ZHANG ${ }^{2}$ \\ ${ }^{1}$ First Affiliated Hospital, Xi'an Jiaotong University, Xi'an, Shaanxi 710061; ${ }^{2}$ Department of Gastroenterology, \\ Tangdu Hospital, Fourth Military Medical University, Xi'an, Shaanxi 710038, P.R. China
}

Received February 3, 2013; Accepted October 2, 2013

DOI: $10.3892 / \mathrm{mco} .2013 .209$

\begin{abstract}
Weight gain commonly occurs in breast cancer patients who receive adjuvant chemotherapy. Weight gain may cause psychosocial stress and is associated with patient prognosis and survival. Several factors contributing to weight gain have been identified in Western populations. However, there was lack of information associated with body weight changes following adjuvant chemotherapy in Chinese breast cancer patients. To the best of our knowledge, this is the first such study to be conducted in the Chinese population. A total of 98 patients who received adjuvant chemotherapy following a modified radical mastectomy were included in this study. Their weight was measured prior to the first and following the last cycle of chemotherapy. A weight gain, or loss, of $>1 \mathrm{~kg}$ following adjuvant chemotherapy was considered to be significant. Cancer stage, treatment modalities, menopausal status and other clinical information were obtained through medical record review. The results revealed that the weight changes ranged from -11 to $+9 \mathrm{~kg}$, with a mean value of $-0.4 \pm 4.4 \mathrm{~kg}$. A total of $66.7 \%$ of the patients exhibited weight changes $(34.6 \%$ gained $>1 \mathrm{~kg}$ and $32.1 \%$ lost weight), whereas $33.3 \%$ of the patients maintained a stable weight $(\mathrm{P}<0.001)$. Patients aged $\leq 40$ years [odds ratio $(\mathrm{OR})=1.429, \mathrm{P}=0.028$ ], with a weight of $\geq 60 \mathrm{~kg}$ at diagnosis $(\mathrm{OR}=2.211, \mathrm{P}=0.023)$, who received $\geq 4$ cycles of chemotherapy $(\mathrm{OR}=1.591, \mathrm{P}=0.039)$ and a total hormone dose of $\geq 200 \mathrm{mg}(\mathrm{OR}=2.75, \mathrm{P}=0.013)$ exhibited a higher risk of weight gain. In conclusion, the body weight changes observed in Chinese breast cancer patient post-adjuvant chemotherapy were different from those observed among Western populations, represented predominantly by weight gain and were reflected by approximately equal percentages of weight gain, stable weight and weight loss.
\end{abstract}

Correspondence to: Professor Jian-Sheng Wang, First Affiliated Hospital, Xi'an Jiaotong University, 277 Yanta West Road, Xi'an, Shaanxi 710061, P.R. China

E-mail: wangjshxjtu@gmail.com

*Contributed equally

Key words: breast cancer, adjuvant chemotherapy, body weight changes

\section{Introduction}

Over the previous two decades, weight gain has been shown to be a dominant event among Western breast cancer patients following adjuvant chemotherapy, exerting a negative effect on the quality of life of the patients, since weight gain is associated with secondary diseases, such as diabetes and cardiovascular diseases (1-7). Furthermore, weight gain is also associated with cancer recurrence and poor prognosis (8-13). Several previous studies have demonstrated that the majority of breast cancer survivors exhibited a mean body weight gain of 1-6 kg following chemotherapy and identified adjuvant chemotherapy as an independent prognostic factor for weight gain, with a potential long-term effect $(2,3,5,6,11)$. However, other studies did not report a significant difference in weight gain between breast cancer patients receiving adjuvant chemotherapy and healthy controls (14). Therefore, the frequency and extent of body weight gain reported by previous studies may be considered to be overestimated $(14,15)$.

The causes of weight gain may include reduced physical activity and menopause prior to diagnosis. However, the exact mechanisms have not been fully elucidated. In addition, the previous observations were focused on patients from the USA and also patients from Western Europe. The lack of available information associated with body weight changes in Chinese breast cancer patients following adjuvant chemotherapy prompted the investigation of the type of weight changes exhibited by Chinese breast cancer survivors and the analysis of the potential factors contributing to these changes.

\section{Patients and methods}

Study population. This was a retrospective, observational, single-centre study conducted on women with stage I-IIIA primary breast cancer who received adjuvant chemotherapy at the First Affiliated Hospital of Xi'an Jiaotong University, between 2010 and 2012. All patients underwent modified radical mastectomies and had pathologically confirmed invasive non-specific ductal carcinoma. Patients were excluded if they presented with distant metastases or additional cancer(s), or if their records did not integrate.

This study was approved by the Institutional Review Board of the First Affiliated Hospital of Xi'an Jiaotong University. Written informed consent was obtained from the subjects and 
Table I. Clinical characteristics of the patients.

\begin{tabular}{lcc}
\hline Characteristics & Patient no. & Percentage \\
\hline Menopausal status & & 54.5 \\
Premenopausal & 53 & 45.5 \\
Postmenopausal & 45 & 30.6 \\
Stage & 30 & 41.8 \\
I & 41 & 27.6 \\
II & 27 & 42.9 \\
III & & 57.1 \\
Chemotherapy regimens & 42 & \\
Anthracycline-based regimens & 56 & \\
Anthracycline combined with taxane & $48.6 \pm 9.5$ & \\
Age, years (means \pm SD) & $58.6 \pm 9.1$ & \\
Weight, kg (mean \pm SD) & & \\
\hline
\end{tabular}

Table II. Weight changes following chemotherapy.

\begin{tabular}{|c|c|c|c|c|c|c|c|c|c|}
\hline \multirow{2}{*}{ Values } & \multirow{2}{*}{ Total } & \multirow{2}{*}{ Stable } & \multicolumn{6}{|c|}{ Weight changes } & \multirow{2}{*}{ P-value } \\
\hline & & & & Loss & & & Gain & & \\
\hline Range (kg) & -11 to 9 & -1 to 1 & $>10$ & $5-10$ & $1-5$ & $1-5$ & $5-10$ & $>10$ & $<0.001$ \\
\hline Percentage $(\%)$ & 100 & 33.3 & 2.1 & 13.7 & 16.3 & 23.4 & 11.2 & 0 & \\
\hline
\end{tabular}

all clinical investigations were conducted according to the principles expressed in the Declaration of Helsinki.

Data collection. All information, including body weight, tumor status, age at diagnosis, menopausal status, receptor status, chemotherapy regimen, number of chemotherapy cycles and total hormone dosage, were obtained through reviewing medical records. Body weight change was defined as the difference in body weight between day 1 of the first chemotherapy cycle and the last day of the last cycle. A weight gain or loss of $>1 \mathrm{~kg}$ following adjuvant chemotherapy was considered to be significant, whereas weight changes ranging between 1 and $-1 \mathrm{~kg}$ were considered to indicate a stable weight. Data on menopausal status at diagnosis were only included if recorded within 3 months prior to or after diagnosis.

Statistical analysis. Categorical variables were expressed as frequencies and percentages. Continuous variables were calculated as means $\pm \mathrm{SD}$. A two-way repeated measures analysis of variance (ANOVA) was used to compare the means of repeated body weight measurements. The t-test and $\chi^{2}$ test were used to compare the differences in the frequency and magnitude of the weight changes. The associations between weight change and factors such as age and weight at diagnosis, menopausal status, receptor status, clinical stage, regimen and cycle of chemotherapy and hormone dosage, were assessed by univariate analysis (such as logistic regression model, linear correlation and linear regression analysis) and multivariate logistic regression analysis. $\mathrm{P}=0.05$ was considered to indicate a statistically significant difference. All statistical analyses were conducted using SPSS software, version 13.0 (SPSS Inc., Chicago, IL, USA).

\section{Results}

Subject demographic data. A total of 98 female breast cancer patients who underwent modified radical mastectomy and received adjuvant chemotherapy at the First Affiliated Hospital of Xi'an Jiaotong University between 2010 and 2012 were included in this study. The median number of chemotherapy cycles was 3.8 and the median observation time was 2.1 months. The clinicopathological characteristics of the patients are summarized in Table I. The mean age at diagnosis was 48.6 years $(\mathrm{SD}=9.5)$ and the mean weight prior to the initiation of chemotherapy was $58.6 \mathrm{~kg}(\mathrm{SD}=9.1)$. A total of $54.5 \%$ of the patients were premenopausal and the remaining $45.5 \%$ were postmenopausal. All patients had stage I-III disease, with $30.6 \%$ of the patients at stage I, $41.8 \%$ at stage II and $27.6 \%$ at stage III (Table I).

Changes in body weight following adjuvant chemotherapy. The majority of the studies from Western countries reported that breast cancer patients exhibited weight gain following chemotherapy. In our study, approximately two thirds of the patients exhibited weight changes, with $34.6 \%$ of the patients presenting with a weight gain of $>1 \mathrm{~kg}$ and $32.1 \%$ with weight loss. The weight changes ranged from -11 to $+9 \mathrm{~kg}$. There was no statistically significant difference between weight gain, weight loss and stable weight $(\mathrm{P}=0.519)$. However, the changes in body weight (combined gain and loss vs. stable weight) were 
Table III. Analysis of variance in weight repeated measurement.

\begin{tabular}{|c|c|c|c|c|c|}
\hline Source of differences & SS & Df & MS & $\mathrm{F}$ & P-value \\
\hline Total variation & $13,428.060$ & 95 & 141.348 & - & - \\
\hline Chemotherapy & $2,274.625$ & 2 & $1,137.313$ & 5.539 & 0.012 \\
\hline Individual error & $4,311.697$ & 21 & 205.319 & - & - \\
\hline Time & $1,017.017$ & 3 & 339.006 & 4.782 & 0.005 \\
\hline Time $\mathrm{x}$ chemotherapy & $1,358.804$ & 6 & 226.467 & 3.195 & 0.008 \\
\hline Intra-individual error & $4,465.917$ & 63 & 70.888 & - & - \\
\hline
\end{tabular}

SS, sum of squares; Df, degree of freedom; MS, mean squares; F, F-value.

Table IV. Comparison of weight changes between subgroups.

\begin{tabular}{|c|c|c|}
\hline Factors & $\begin{array}{l}\text { Weight changes } \\
(\text { mean } \pm \mathrm{SD}, \mathrm{kg})\end{array}$ & P-value \\
\hline Age (years) & & 0.027 \\
\hline$\leq 40$ & $1.1 \pm 3.6$ & \\
\hline $40-50$ & $-0.3 \pm 4.5$ & \\
\hline$\geq 50$ & $-1.2 \pm 4.6$ & \\
\hline Weight (kg) & & 0.013 \\
\hline$\leq 50$ & $0.3 \pm 5.2$ & \\
\hline $50-60$ & $1.3 \pm 3.5$ & \\
\hline$\geq 60$ & $-1.8 \pm 3.8$ & \\
\hline Menopausal status & & 0.924 \\
\hline Premenopausal & $-0.4 \pm 4.4$ & \\
\hline Postmenopausal & $-0.5 \pm 5.5$ & \\
\hline Receptor status & & 0.222 \\
\hline $\mathrm{ER}$ or $\mathrm{PR}^{+} / \mathrm{HER} 2^{+}$ & $-0.5 \pm 3.9$ & \\
\hline $\mathrm{ER}$ or $\mathrm{PR}^{+} / \mathrm{HER} 2^{-}$ & $-1.2 \pm 4.9$ & \\
\hline ER or PR ${ }^{-} / \mathrm{HER} 2^{+}$ & $0.9 \pm 3.1$ & \\
\hline ER or PR $/$ HER2- & $-0.5 \pm 5.1$ & \\
\hline Stage & & 0.231 \\
\hline I & $-1.4 \pm 4.1$ & \\
\hline II & $0.5 \pm 4.4$ & \\
\hline III & $-0.6 \pm 5.0$ & \\
\hline Chemotherapy regimens & & 0.150 \\
\hline Anthracycline-based & $-0.6 \pm 3.9$ & \\
\hline $\begin{array}{l}\text { Anthracycline combined } \\
\text { with taxane }\end{array}$ & $-0.2 \pm 4.6$ & \\
\hline Chemotherapy cycles (no.) & & 0.037 \\
\hline$<4$ & $-1.5 \pm 4.6$ & \\
\hline$\geq 4$ & $0.4 \pm 4.1$ & \\
\hline Hormone dosage (mg) & & 0.038 \\
\hline$\leq 100$ & $-0.9 \pm 3.8$ & \\
\hline $100-200$ & $0.5 \pm 5.1$ & \\
\hline$\geq 200$ & $1.3 \pm 4.8$ & \\
\hline
\end{tabular}

ER, estrogen receptor; PR, progesterone receptor; HER2, human epidermal growth factor receptor 2 ; SD, standard deviation. distinct $(\mathrm{P}<0.001$, Table II). Furthermore, the two-way repeated measures ANOVA demonstrated that adjuvant chemotherapy and the duration of chemotherapy were factors contributing to these statistically significant differences $(\mathrm{P}=0.012$ and 0.005 , respectively; Table III).

Furthermore, the patients were subdivided into several subgroups according to the differences in age and weight at diagnosis, menopausal status, receptor status, clinical stage, chemotherapeutic regimen, number of chemotherapy cycles and hormone dosage, and the weight changes were compared between those subgroups. As shown in Table IV, there were statistically significant differences in the weight changes between the age, weight at diagnosis, number of chemotherapy cycles and hormone dosage subgroups $(\mathrm{P}=0.027,0.013,0.037$ and 0.038 , respectively).

Factors affecting weight gain following chemotherapy. Considering the differences in the weight changes presented in Table IV, the age and weight at diagnosis, number of chemotherapy cycles and hormone dosage may be considered to be risk factors for weight gain among Chinese breast cancer patients. Using the univariate analysis, these four variables were found to be significant in predicting weight gain following adjuvant chemotherapy (Table V). Age at diagnosis $\leq 40$ years [odds ratio $(\mathrm{OR})=1.429, \mathrm{P}=0.028$ ], weight at diagnosis $\geq 60 \mathrm{~kg}$ (OR=2.211, $\mathrm{P}=0.023)$, number of chemotherapy cycles $\geq 4$ $(\mathrm{OR}=1.591, \mathrm{P}=0.039)$ and total dose of hormones $\geq 200 \mathrm{mg}$ $(\mathrm{OR}=2.750, \mathrm{P}=0.013)$ significantly increased the risk of body weight gain following chemotherapy. Furthermore, the univariate linear correlation and regression analysis demonstrated that the body weight at diagnosis was negatively correlated with weight gain $\left(\mathrm{r}=-0.355, \mathrm{R}^{2}=0.126, \mathrm{P}<0.05\right)$. By contrast, the hormone dosage used in chemotherapy was positively correlated with weight gain $\left(\mathrm{r}=0.111, \mathrm{R}^{2}=0.012, \mathrm{P}<0.05\right)($ Table VI). We also conducted a multivariate logistic regression analysis to confirm the effect of these four factors on weight gain and the results are presented in Table VII. The $\mathrm{P}$ value for each factor was $0.019,0.016,0.019$ and 0.018 , respectively.

\section{Discussion}

Several previous studies have demonstrated that adjuvant chemotherapy correlates with weight changes in Western 
Table V. Factors affecting weight gain according to univariate analysis.

\begin{tabular}{|c|c|c|c|}
\hline Factors & Percentage of weight gain $(\%)$ & OR $(95 \% \mathrm{CI})$ & P-value \\
\hline \multicolumn{4}{|l|}{ Age (years) } \\
\hline$\leq 40$ & 44.4 & $1.429(1.040-5.099)$ & 0.028 \\
\hline $40-50$ & 25.0 & 1 & \\
\hline$\geq 50$ & 25.0 & $0.955(0.623-1.463)$ & 0.830 \\
\hline \multicolumn{4}{|l|}{ Weight (kg) } \\
\hline$\leq 50$ & 50.0 & 1 & \\
\hline $50-60$ & 39.9 & $0.583(0.226-1.509)$ & 0.236 \\
\hline$\geq 60$ & 10.1 & $2.211(1.580-8.321)$ & 0.023 \\
\hline \multicolumn{4}{|l|}{ Menopausal status } \\
\hline Premenopausal & 31.0 & 1 & \\
\hline Postmenopausal & 27.8 & $1.034(0.414-2.581)$ & 0.943 \\
\hline \multicolumn{4}{|l|}{ Receptor status } \\
\hline $\mathrm{ER}$ or $\mathrm{PR}^{+} / \mathrm{HER} 2^{+}$ & 26.7 & $0.800(0.209-3.064)$ & 0.744 \\
\hline ER or $\mathrm{PR}^{+} / \mathrm{HER} 2^{-}$ & 26.1 & 1 & \\
\hline ER or PR ${ }^{-} / \mathrm{HER} 2^{+}$ & 23.5 & $0.591(0.298-1.175)$ & 0.131 \\
\hline ER or PR $/$ HER2 $^{-}$ & 38.5 & $1.507(0.482-4.710)$ & 0.367 \\
\hline \multicolumn{4}{|l|}{ Stage } \\
\hline $\mathrm{I}$ & 24.1 & 1 & \\
\hline II & 36.1 & $0.933(0.443-1.968)$ & 0.855 \\
\hline III & 33.3 & $1.190(0.461-3.071)$ & 0.717 \\
\hline \multicolumn{4}{|l|}{ Chemotherapy regimens } \\
\hline Anthracycline-based & 22.2 & 1 & \\
\hline Anthracycline combined with taxane & 33.3 & $1.653(0.958-2.850)$ & 0.077 \\
\hline \multicolumn{4}{|l|}{ Chemotherapy cycles (no.) } \\
\hline$<4$ & 22.5 & 1 & \\
\hline$\geq 4$ & 41.8 & $1.591(1.166-2.034)$ & 0.039 \\
\hline \multicolumn{4}{|l|}{ Hormone dosage (mg) } \\
\hline$\leq 100$ & 20.5 & 1 & \\
\hline $100-200$ & 41.7 & $1.639(1.500-3.520)$ & 0.024 \\
\hline$\geq 200$ & 40.9 & $2.750(1.080-7.000)$ & 0.013 \\
\hline
\end{tabular}

OR, odds ratio; CI, confidence interval; ER, estrogen receptor; PR, progesterone receptor; HER2, human epidermal growth factor receptor 2.

Table VI. Univariate linear correlation and linear regression analyses for different factors affecting weight gain.

\begin{tabular}{lccccc}
\hline & \multicolumn{2}{c}{ Linear correlation } & & \multicolumn{2}{c}{ Linear regression } \\
\cline { 2 - 3 } Factors & $\mathrm{r}$ & P-value & & $\mathrm{R}^{2}$ & P-value \\
\hline Age & 0.085 & 0.487 & & 0.007 & 0.552 \\
Weight & -0.355 & 0.001 & & 0.126 & 0.002 \\
Periodicity & 0.197 & 0.084 & & 0.039 & 0.084 \\
Hormone dosage & 0.111 & 0.017 & & 0.012 & 0.033 \\
\hline
\end{tabular}

$\mathrm{r}$, correlation coefficient; $\mathrm{R}^{2}$, coefficient of determination.

breast cancer patients, the majority of which reported body weight gain $(4,5,16-20)$. In our study, Chinese patients with operable breast cancer exhibited significant weight changes
Table VII. Multivariate logistic regression analysis for different factors affecting weight gain.

\begin{tabular}{lcccc}
\hline Factors & B & SE & Wald & P-value \\
\hline Age & -1.382 & 0.587 & 5.536 & 0.019 \\
Weight & -3.748 & 1.560 & 5.776 & 0.016 \\
Periodicity & 1.214 & 0.519 & 5.480 & 0.019 \\
Hormone dosage & 1.207 & 0.512 & 5.556 & 0.018 \\
\hline \multirow{2}{*}{ B, unstandardized regression coefficient; SE, standard error. } \\
\hline
\end{tabular}

following adjuvant chemotherapy (66.7 with altered vs. $33.3 \%$ with stable weight, $\mathrm{P}<0.05)$. Thus, unlike the dominant weight gain observed in Western populations, only $34.6 \%$ of the Chinese patients included in this study gained weight. However, 
adjuvant chemotherapy as an independent predictive factor for weight gain has been debated upon $(14,16)$. Considering the limitation that we did not involve analyses of the endocrine therapy or combined systemic treatment, our study exhibits reduced power in identifying adjuvant chemotherapy as an independent factor affecting weight changes.

We observed that the differences in age and weight at diagnosis, number of chemotherapy cycles and hormone dosage may be associated with the differences in body weight changes. As shown in Table IV, the mean weight change of patients with an age of $\leq 40$ years and a weight of $<60 \mathrm{~kg}$ at diagnosis, who received $\geq 4$ cycles of chemotherapy and $\geq 100 \mathrm{mg}$ hormone dosage, was higher following adjuvant chemotherapy. However, subgroups with different clinical characteristics, such as menopausal status, receptor status, clinical stage and chemotherapeutic regimens, did not exhibit significant differences in body weight changes.

Since weight gain may affect the outcome and compliance of breast cancer patients $(21,22)$, we should assess the effects of multiple factors on weight gain for the prevention of breast cancer. There are several factors contributing to weight gain following adjuvant chemotherapy, such as age and weight at diagnosis, menopausal status, chemotherapeutic regimen, receptor status, clinical stage and number of chemotherapy cycles. Other factors, such as lifestyle, educational level and economical status were also shown to affect weight gain (23). In this study, we demonstrated that patients aged $\leq 40$ years at diagnosis were more likely to gain weight compared to those aged $>40$ years. Consistent with the results reported by Rock et al (24), the multivariate logistic regression analysis indicated that age at diagnosis was independently negatively associated with weight gain (Table VII).

The body weight at diagnosis was also shown to be an important factor contributing to weight gain (24). Patients with a body weight of $\geq 60 \mathrm{~kg}$ exhibited a $\sim 2$-fold higher risk of weight gain following adjuvant chemotherapy. Moreover, our results also identified weight at diagnosis as an independent negative predictive factor for weight gain $(\mathrm{r}=-0.355$, $\mathrm{B}=-3.748, \mathrm{P}<0.05)$, with a weak linear correlation $(\mathrm{r}=-0.355$, $\left.\mathrm{R}^{2}=0.126, \mathrm{P}<0.05\right)$.

The menopausal status was previously reported to be a positive predictor for weight gain in women receiving adjuvant chemotherapy (24-26), although it was also reported that menopausal status did not affect body weight (27). Our data suggested that there was no significant correlation between menopausal status and weight changes in Chinese breast cancer patients following adjuvant chemotherapy. However, due to the limitations of the scale of this study, this subject requires further investigation.

Glucocorticoids are widely used to prevent several side effects of chemotherapy; however, they may affect body weight. Goodwin et al (28) observed that patients treated with cyclophosphamide, methotrexate and fluorouracil (CMF) plus prednisolone and ovarian ablation gained more weight compared to those treated with CMF alone $(5.55$ vs. $2.51 \mathrm{~kg}$, respectively; $\mathrm{P}<0.001)$. However, that study did not eliminate the effect of ovarian ablation on weight. To the best of our knowledge, this study demonstrated for the first time that glucocorticoid administration significantly increased body weight in Chinese patients.
Our study had several limitations, due to its retrospective data from a single center and the relatively small sample size. Random measurement errors may occur with regard to different timing and methods of body weight measurements. Therefore, the power of identifying significant differences was limited. Additionally, we did not assess additional factors which would potentially affect weight change, including energy intake, exercise, education and psychological status. Further multicenter, long-term and random case-control studies are required to further address these issues. However, this study was the first to report that adjuvant chemotherapy may be associated with weight change in Chinese breast cancer patients. The differences between Chinese and Western populations may be attributed to racial genetic differences, a subject that requires further investigation.

\section{Acknowledgements}

The authors would like to thank Dr Yan $\mathrm{Xu}$ for the proofreading and language modification of this study.

\section{References}

1. Dixon JK, Moritz DA and Baker FL: Breast cancer and weight gain: an unexpected finding. Oncol Nurs Forum 5: 5-7, 1978.

2. Saquib N, Flatt SW, Natarajan L, et al: Weight gain and recovery of pre-cancer weight after breast cancer treatments: evidence from the women's healthy eating and living (WHEL) study. Breast Cancer Res Treat 105: 177-186, 2007.

3. Heideman WH, Russell NS, Gundy C, Rookus MA and Voskuil DW: The frequency, magnitude and timing of postdiagnosis body weight gain in Dutch breast cancer survivors. Eur J Cancer 45: 119-126, 2009.

4. Demark-Wahnefried W, Peterson BL, Winer EP, et al: Changes in weight, body composition, and factors influencing energy balance among premenopausal breast cancer patients receiving adjuvant chemotherapy. J Clin Oncol 19: 2381-2389, 2001.

5. Goodwin PJ, Ennis M, Pritchard KI, et al: Adjuvant treatment and onset of menopause predict weight gain after breast cancer diagnosis. J Clin Oncol 17: 120-129, 1999.

6. Irwin ML, McTiernan A, Baumgartner RN, et al: Changes in body fat and weight after a breast cancer diagnosis: influence of demographic, prognostic, and lifestyle factors. J Clin Oncol 23: 774-782, 2005.

7. Tredan O, Bajard A, Meunier A, et al: Body weight change in women receiving adjuvant chemotherapy for breast cancer: a French prospective study. Clin Nutr 29: 187-191, 2010.

8. Kroenke CH, Chen WY, Rosner B and Holmes MD: Weight, weight gain, and survival after breast cancer diagnosis. J Clin Oncol 23: 1370-1378, 2005.

9. McTiernan A: Obesity and cancer: the risks, science, and potential management strategies. Oncology (Williston Park) 19: 871-881; discussion 881-882, 885-886, 2005.

10. Caan BJ, Emond JA, Natarajan L, et al: Post-diagnosis weight gain and breast cancer recurrence in women with early stage breast cancer. Breast Cancer Res Treat 99: 47-57, 2006.

11. Demark-Wahnefried W, Aziz NM, Rowland JH and Pinto BM: Riding the crest of the teachable moment: promoting long-term health after the diagnosis of cancer. J Clin Oncol 23: 5814-5830, 2005.

12. Herman DR, Ganz PA, Petersen L and Greendale GA: Obesity and cardiovascular risk factors in younger breast cancer survivors: The Cancer and Menopause Study (CAMS). Breast Cancer Res Treat 93: 13-23, 2005.

13. Trentham-Dietz A, Newcomb PA, Nichols HB and Hampton JM: Breast cancer risk factors and second primary malignancies among women with breast cancer. Breast Cancer Res Treat 105: 195-207, 2007.

14. Freedman RJ, Aziz N, Albanes D, et al: Weight and body composition changes during and after adjuvant chemotherapy in women with breast cancer. J Clin Endocrinol Metab 89: 2248-2253, 2004. 
15. Ingram $\mathrm{C}$ and Brown $\mathrm{JK}$ : Patterns of weight and body composition change in premenopausal women with early stage breast cancer: has weight gain been overestimated? Cancer Nurs 27 483-490, 2004.

16. Camoriano JK, Loprinzi CL, Ingle JN, Therneau TM, Krook JE and Veeder MH: Weight change in women treated with adjuvant therapy or observed following mastectomy for node-positive breast cancer. J Clin Oncol 8: 1327-1334, 1990.

17. DeGeorge D, Gray JJ, Fetting JH and Rolls BJ: Weight gain in patients with breast cancer receiving adjuvant treatment as a function of restraint, disinhibition, and hunger. Oncol Nurs Forum 17 (Suppl 3): 23-30, 1990.

18. Demark-Wahnefried W, Winer EP and Rimer BK: Why women gain weight with adjuvant chemotherapy for breast cancer. J Clin Oncol 11: 1418-1429, 1993.

19. Demark-Wahnefried W, Hars V, Conaway MR, et al: Reduced rates of metabolism and decreased physical activity in breast cancer patients receiving adjuvant chemotherapy. Am J Clin Nutr 65: 1495-1501, 1997

20. McInnes JA and Knobf MT: Weight gain and quality of life in women treated with adjuvant chemotherapy for early-stage breast cancer. Oncol Nurs Forum 28: 675-684, 2001.

21. Sestak I, Harvie M, Howell A, Forbes JF, Dowsett M and Cuzick J: Weight change associated with anastrozole and tamoxifen treatment in postmenopausal women with or at high risk of developing breast cancer. Breast Cancer Res Treat 134: 727-734, 2012.
22. Caan BJ, Emond JA, Su HI, et al: Effect of postdiagnosis weight change on hot flash status among early-stage breast cancer survivors. J Clin Oncol 30: 1492-1497, 2012.

23. Villarini A, Pasanisi P, Raimondi M, et al: Preventing weight gain during adjuvant chemotherapy for breast cancer: a dietary intervention study. Breast Cancer Res Treat 135: 581-589, 2012.

24. Rock CL, Flatt SW, Newman V, et al: Factors associated with weight gain in women after diagnosis of breast cancer. Women's Healthy Eating and Living Study Group. J Am Diet Assoc 99: 1212-1221, 1999.

25. Shapiro CL and Recht A: Side effects of adjuvant treatment of breast cancer. N Engl J Med 344: 1997-2008, 2001.

26. Basaran G, Turhal NS, Cabuk D, et al: Weight gain after adjuvant chemotherapy in patients with early breast cancer in Istanbul Turkey. Med Oncol 28: 409-415, 2011.

27. Lankester KJ, Phillips JE and Lawton PA: Weight gain during adjuvant and neoadjuvant chemotherapy for breast cancer: an audit of 100 women receiving FEC or CMF chemotherapy. Clin Oncol (R Coll Radiol) 14: 64-67, 2002.

28. Goodwin PJ, Panzarella T and Boyd NF: Weight gain in women with localized breast cancer - a descriptive study. Breast Cancer Res Treat 11: 59-66, 1988. 